\title{
Yield of CT pulmonary angiography in the diagnosis of acute pulmonary embolism: short report
}

\author{
Zhongyi Chen', Simon Deblois², Kevin Toporowicz' ${ }^{1}$, rina Boldeanu' ${ }^{1}$, Marie-Odile Francoeur ${ }^{1}$, Manel Sadouni ${ }^{1,3}$, \\ Luigi Lepanto ${ }^{1,2}$ and Carl Chartrand-Lefebvre ${ }^{1,3^{*}}$ (D)
}

\begin{abstract}
Objective: To assess computed tomography pulmonary angiography (CTPA) positive yield rate for pulmonary embolism (PE) in a Canadian academic tertiary center.

Results: This one-center retrospective cross-sectional study includes from 5565 (model 1) to 5296 (model 2) patients that were evaluated for suspected PE in 2015, among which 1331 (23.9\% (model 1) to 25.1\% (model 2)) underwent CTPA. Mean age of CTPA patients was $60.2 \pm 16.6$ years, of which 575 were males (43.2\%). Two hundred eleven CTPA examinations were positive for PE, giving a CTPA positive yield rate of $15.9 \%$ (95\% Cl (13.93-17.87)). One hundred and thirteen (8.1\%) CTPA were considered indeterminate, and eleven were considered nondiagnostic (0.8\%). Among the 211 CTPA positive for PE, 67 (32\%) were proximal emboli, 98 (47\%) were segmental emboli and 44 (21\%\%) were subsegmental emboli. In conclusion, in this retrospective study done in a Canadian academic tertiary center, we report a positive rate of $15.9 \%$ for PE detection with CTPA, which is above the generally accepted lower threshold of 10\% for the yield of CTPA.
\end{abstract}

Keywords: Pulmonary embolism, Computed tomography, Oversuse, Yield rate

\section{Introduction}

In the recent years, the increasing use of pulmonary computed tomography angiography (CTPA) in the evaluation of suspected pulmonary embolism (PE) has raised the issue of overuse. One argument for an overuse of CTPA is a low positive yield rate, i.e. a low positivity rate for PE. Although a definitive ideal positivity rate for CTPA has not been established, a $10 \%$ rate is generally accepted as the threshold under which overuse of CTPA should be considered $[1,2]$. Another possible concern is the tendency of CTPA to overdiagnose clinically insignificant cases of PE, as evidenced by the lack of improvement in mortality rate of PE after the introduction of CTPA [3]. We would like to report the results of a study assessing

\footnotetext{
*Correspondence: chartrandlef@videotron.ca

${ }^{1}$ Department of Radiology, Centre Hospitalier de I'Université de Montréal (CHUM), 1051 Sanguinet Street, Montréal, QC H2X 0C1, Canada

Full list of author information is available at the end of the article
}

CTPA yield for PE done in our medical center, a Canadian academic tertiary center.

\section{Main text \\ Materials and methods \\ Study design}

It is a retrospective cross-sectional study that included all patients at the University of Montreal Medical Center (CHUM) suspected of acute PE between January and December 2015 (inclusive). Approval was obtained from the CHUM institutional review board (16.091) and the requirement for informed consent was waived.

\section{PE models}

Two models were used to retrospectively identify patients being suspected of PE. In model 1, patients were considered as being suspected of PE if they underwent at least one of the following tests: D-dimer dosage, CTPA or ventilation-perfusion scintigraphy. In model 2 , the 
same search criteria were used, except that patients who underwent venous Doppler of lower limb(s) were subtracted from the patients who had D-dimer testing.

\section{Data collection}

Data were gathered from the CHUM's electronic medical records system. In the CHUM, CT scanners used at the time of the study were 64- to 256-slice systems. Most CTPA examinations were interpreted by cardiothoracic radiologists. A minority of examinations were interpreted by non-cardiothoracic radiologists, especially offhours. All on-call interpretations by a radiology resident is reviewed by a staff radiologist, and recorded in the final report.

The following information was gathered from the radiology reports: age, sex, scan result with location of the most proximal embolus if applicable, and relevant clinical data written on the request (hemoptysis, dyspnea, chest pain, syncope, desaturation, signs of right-sided heart failure).

CTPA results from the radiology reports were classified as positive (presence of $\mathrm{PE}$ ), negative (absence of $\mathrm{PE}$ ), indeterminate or nondiagnostic. A CTPA was classified as positive for PE when the radiologist's interpretation showed a definitive diagnosis of PE; clear absence of PE was classified as a negative result; presence of intraluminal images doubtful for PE, due to artefacts, suboptimal opacification or to other causes was classified as indeterminate; a nondiagnostic result was used when no clear information could be drawn from the CT angiogram. For positive CT angiograms, the arterial level (main, lobar, segmental or subsegmental) of the most proximal PE was noted.

\section{Statistical analysis}

Continuous variables are expressed as mean \pm standard deviation (SD), and categorical variables are expressed as count (percentage of total), unless otherwise specified. Descriptive statistics were compiled using spreadsheet software (Microsoft Excel 2013 (Microsoft corp., Redmond, USA)). CT positive yield rate is defined as the quotient of number of positive CT scans/total number of CT scans. Further statistical analyses were done using software (SPSS version 23 (IBM corp., Armonk, USA)). $\mathrm{P}$-values less than 0.05 were considered statistically significant.

\section{Results}

In total, from 5565 (model 1) to 5296 (model 2) patients were evaluated for suspected PE in the CHUM in 2015, among which 1331 (23.9\% (model 1) to $25.1 \%$ (model 2)) underwent CTPA. Mean age of CTPA patients was $60.2 \pm 16.6$ years, of which 575 were males (43.2\%).
Demographics of patients who underwent CTPA are summarized in Table 1. Two hundred eleven CTPA examinations were positive for PE, giving a CTPA positive yield rate of $15.9 \%$ (95\% CI (13.93-17.87)). One hundred and thirteen (8.1\%) CTPA were considered indeterminate, and eleven were considered nondiagnostic $(0.8 \%)$.

Among the 211 CTPA positive for PE, 67 (32\%) were proximal emboli, 98 (47\%) were segmental emboli and 44 $(21 \% \%)$ were subsegmental emboli (Table 2 ).

\section{Discussion}

In a recent systematic review done by our group, the baseline diagnostic yield of CTPA for PE was shown to vary from 4.7 to $31 \%$ [4]. In 7 (58\%) out of the 12 included studies in this review, the diagnostic yield was lower than the generally accepted threshold of $10 \%[1,2]$. Using this $10 \%$ cut-off, 3 of the high-yield studies were from the United States (US), as well as one from Spain and another from Australia. In comparison, all low-yield studies were from the US, raising the possibility that decreased CTPA yields in US medical centers could reflect concern for malpractice litigation, as was suggested by previous authors [2, 5]. Of note, a recent study of Sharma and Lucas from Scotland [6] shows a positive yield of CTPA for PE over $10 \%$, like ours and another study conducted in another academic center in Canada [7].

CTPA provides accurate and readily available information to the ordering physician on the presence or absence of PE, as well as on other chest pathologies. This is why it could be tempting to use CTPA as a onestop tool for the diagnosis of PE. However, it should be remembered that CTPA has been validated as part of clinical decision rules $[8,9]$, involving the application of a pre-test clinical assessment (Wells criteria, PERC, Charlotte rule, Geneva score, for example) as well as D-dimer testing when clinically relevant. Moreover,

\begin{tabular}{ll}
$\begin{array}{l}\text { Table } 1 \text { Demographics and symptoms of patients who } \\
\text { underwent CTPA }\end{array}$ \\
\hline Number of CTPA scans & $\mathbf{1 3 3 1}$ \\
\hline Age (years) & $60.2 \pm 16.6$ \\
Male sex ( $)$ & $575(43.2)$ \\
Hemoptysis $(n)$ & $610(45.9)$ \\
Dyspnea $(n)$ & $390(29.3)$ \\
Chest pain $(n)$ & $417(31.4)$ \\
Syncope $(n)$ & $340(25.6)$ \\
Desaturation $(n)$ & $147(11.1)$ \\
Signs of right-sided heart failure $(n)$ & $16(1.20)$ \\
\hline
\end{tabular}

Numbers in parentheses are percentages. Signs and symptoms were collected from the scan requests 
Table 2 Pulmonary emboli by location ( $N=211$ CTPA positive for $\mathrm{PE}$ )

\begin{tabular}{ll}
\hline Most proximal location & $\begin{array}{l}\text { Number } \\
\text { of positive } \\
\text { CTPAs }\end{array}$ \\
\hline Main pulmonary artery & $23(11.1)$ \\
Lobar & $44(21.1)$ \\
Segmental & $98(46.9)$ \\
Sub-segmental & $44(21.1)$ \\
\hline
\end{tabular}

clinical guidelines clearly recommend the use of CTPA as part of these clinical decision rules [10-12]. The choice of a specific rule and D-dimer testing should be based on the prevalence of PE within the clientele's clinical characteristics and characteristics of the health care setting $[13,14]$. Further research is needed to assess the impact of interventions aimed at promoting the use of validated clinical decision algorithms and improving the appropriateness of imaging use in the diagnostic workup of PE.

In conclusion, in this retrospective study done in a Canadian academic tertiary center, we report a positive rate of $15.9 \%$ for PE detection with CTPA, which is above the generally accepted lower threshold of $10 \%$ for the yield of CTPA.

\section{Limitations}

Our study involves no clinical follow-up data. Second, although strict definitions of positive, negative, indeterminate or nondiagnostic results for PE were used, there is still the possibility of classification bias. Finally, this study was performed in an academic center, involving CTPA interpretation by cardiothoracic radiologists in most cases, and it remains possible that our results would be altered in a different context.

\section{Abbreviations}

CTPA: computed tomography pulmonary angiography; PE: pulmonary embolism; CHUM: University of Montreal Medical Center; SD: standard deviation.

\section{Authors' contributions}

The manuscript was drafted by ZC, SD and KT, then revised with assistance of CCL. ZC, KT, IB and MOF contributed to the data collection for the imaging data, and SD and LL for clinical information. ZC, MS and CCL contributed to statistical analyses and interpretation of data. ZC, SD, KT, LL, and CCL contributed to the conception and study design. ZC, SD, KT, MS, and CCL performed critical reviews of intermediate versions of the manuscript. All authors reviewed. All authors read and approved the final manuscript.

\section{Author details}

${ }^{1}$ Department of Radiology, Centre Hospitalier de I'Université de Montréal (CHUM), 1051 Sanguinet Street, Montréal, QC H2X 0C1, Canada. ${ }^{2}$ Health Technology Assessment Unit, CHUM, Montréal, QC, Canada. ${ }^{3}$ Research Centre, CHUM, Montréal, QC, Canada.
Acknowledgements

Computed tomography technologists and research personnel who contributed in this study.

\section{Competing interests}

The authors declare that they have no competing interests.

\section{Availability of data and materials}

The datasets generated and/or analyzed during the current study are available from the corresponding author on reasonable request.

\section{Consent to publish}

Not applicable.

\section{Ethics approval and consent to participate}

Approval was obtained from the Institutional Review Board of the Centre Hospitalier de l'Université de Montréal (CHUM) (16.091) and the requirement for informed consent was waived.

\section{Funding}

ZC was supported by the Programme d'excellence en médecine pour I'initiation en recherche (PREMIER), Medicine Faculty, University of Montreal; CCL is supported by the Département de radiologie, radio-oncologie et médecine nucléaire, University of Montreal and the Radiology Department of the Centre hospitalier de I'Université de Montréal.

\section{Publisher's Note}

Springer Nature remains neutral with regard to jurisdictional claims in published maps and institutional affiliations.

Received: 30 September 2018 Accepted: 11 January 2019

Published online: 18 January 2019

References

1. Costantino MM, Randall G, Gosselin M, et al. CT angiography in the evaluation of acute pulmonary embolus. AJR Am J Roentgenol. 2008;191:471-4.

2. Costa AF, Basseri $H$, Sheikh A, et al. The yield of CT pulmonary angiograms to exclude acute pulmonary embolism. Emerg Radiol. 2014;21:133-41.

3. Wiener RS, Schwartz LM, Woloshin S. Time trends in pulmonary embolism in the United States: evidence of overdiagnosis. Arch Int Med. 2011:171(9):831-7.

4. Deblois S, Chartrand-Lefebvre C, Toporowicz K, et al. Interventions to reduce the overuse of imaging for pulmonary embolism: a systematic review. J Hosp Med. 2018;13:52-61.

5. Stein EG, Haramati LB, Chamarthy M, et al. Success of a safe and simple algorithm to reduce use of CT pulmonary angiography in the emergency department. AJR Am J Roentgenol. 2010;194:392-7.

6. Sharma S, Lucas CD. Increasing use of CTPA for the investigation of suspected pulmonary embolism. Postgrad Med. 2017;129:193-7.

7. Chong J, Lee TC, Attarian A, et al. Association of lower diagnostic yield with high users of CT pulmonary angiogram. JAMA Intern Med. 2018;178:412-3.

8. Stein PD, Fowler SE, Goodman LR, et al. Multidetector computed tomography for acute pulmonary embolism. N Engl J Med. 2006;354:2317-27.

9. Van Belle A, Büller HR, Huisman MV, et al. Effectiveness of managing suspected pulmonary embolism using an algorithm combining clinical probability, D-dimer testing, and computed tomography. JAMA. 2006:295:172-9.

10. Raja AS, Greenberg JO, Qaseem A, Denberg TD, et al. Evaluation of patients with suspected acute pulmonary embolism: best practice advice from the clinical guidelines committee of the American College of Physicians. Ann Intern Med. 2015;163:701-11.

11. Rybicki FJ, Udeson JE, Peacock WF. Appropriate utilization of cardiovascular imaging in emergency department patients with chest pain. JACC. 2016:67:853-79.

12. Konstantinides SV, Torbicki A, Agnelli G, et al. 2014 ESC guidelines on the diagnosis and management of acute pulmonary embolism: the Task 
Force for the Diagnosis and Management of Acute Pulmonary Embolism of the European Society of Cardiology (ESC) Endorsed by the European Respiratory Society (ERS). Eur Heart J. 2014;35:3033-73.

13. Lucassen W, Geersing GJ, Erkens PM, et al. Clinical decision rules for excluding pulmonary embolism: a meta-analysis. Ann Intern Med. 2011;155:448-60.
14. Ceriani E, Combescure C, Le Gal G, et al. Clinical prediction rules for pulmonary embolism: a systematic review and meta-analysis. J Thromb Haemost. 2010;8:957-70.
Ready to submit your research? Choose BMC and benefit from:

- fast, convenient online submission

- thorough peer review by experienced researchers in your field

- rapid publication on acceptance

- support for research data, including large and complex data types

- gold Open Access which fosters wider collaboration and increased citations

- maximum visibility for your research: over $100 \mathrm{M}$ website views per year

At BMC, research is always in progress.

Learn more biomedcentral.com/submissions 